\title{
Geospatial Technology a Solution on Communication Development Case Study: Tourism Management in Albania
}

\author{
Medjon Hysenaj \\ University of Shkoder, Albania
}

\begin{abstract}
Albanian tourism industry recent years has consistently increased and has gained a growing share in the country's GDP. The paper outlines the great potentiality Albanian market can benefit from a well management process of the tourism sector exploiting contemporary technology. GIS technology has gained an undisputed role as the backbone of modern tourism development. Based on the close relation tourism has toward the mapping process we will focus our presentation into the most critical issues the Albanian tourism sector suffers from, communication and information toward both sides visitors and potential sponsors, and how GIS offers the right tools for any analytical or visual aspect. The aim of this paper is to present a group of indexed mapping areas showing the most potential zones for tourism development in Albania working as a mirror to redirect future investments, also increase reliability and effectiveness toward data and terrain decision-making.
\end{abstract}

Keywords: information technologies, ICT, GIS, database, development, tourism JEL classification: O3, Z39

\section{Introduction}

In many countries of the world tourism activity is more important than manufacturing activity both economically and socially. Tourism is one of the world's largest and most rapidly expanding industries, contributing with over ten per cent to global GDP and generating employment for 200 million people, according to annual research by the World Travel \& Tourism Council (WTTC) (Ake, 2001).

GIS technology plays a crucial role to develop the tourism sector. Internet usage in Albania has evolved. In this way the exploitation possibilities of GIS technology as digital mapping through web services has increased substantially. (Sui et al., 2011) A considerable amount of web mapping applications offer solutions focused especially in object location and distribution. GIS offers the possibility to analyse statistical information's based on spatial distribution facilitating information evaluation. Information technologies and tourism are two of the most dynamic motivators of the emerging global economy"(Jovanović et al., 2008)". Investing in tourism sector is as profitable as delicate because it requires detailed analysis of the territory, climate, distances and movements. Digital mapping is essential in performing all these tasks in the fastest and reliable way "(Hysenaj, 2011)".

Albania has a great potentiality in the sector of tourism. Especially last year's tourism in Albania has developed vigorously. According to statistics "(ODA, 2011 )"during the year 2010, more than 2.3 million tourists visited Albania which is quite significant compared to the 2.8 million of the country population. Albania recent years faced a real development in the tourism sector. 
Albania is ranked among the top three assessments for the affinity for Travel \& Tourism are displaying great openness to foreign travellers and with their business communities also expressing their sense of the great value of tourism on offer in their countries. The country ranked 71 out of 139 countries (WEF) from around the globe, ranking ahead of countries with long-established and successful tourism sectors. Compared to 2009 the country increased with 19 places.

The ranking indicates that Albania has excellent growth potential in tourism, and that we can improve it through concrete action by policy makers and the collective efforts of the private, civil and governmental sector. However, it also points to very troubling weakness that could limit severely Albania's competitiveness if not addressed in a coherent way across sectors and Ministerial portfolios"(Lawrence, 2007)".

\section{Strategic Operation}

The WEF report on tourism considers Albania one of the countries with the greatest contrast between natural and management opportunities. On one side Albania is ranked among the countries with the highest natural potentialities but on the other side it positions itself in the last places as belong to the management policy issue. Tourism promotion, natural resource management and accommodation facilities are turning into endemic problematic from which the Albanian tourism is suffering.

The development of a comprehensive web-based digital mapping application, opened for continuous update from reliable sources, integrating indexed mapping related to several issues, will create a new dimension for the problematic conceptualization. The power of GIS lies not only in the ability to visualize spatial relationships, but also beyond the space to a holistic view of the world with its many interconnected components and complex relationships (Kilical et al., 2001).Following we are going to present a set of maps and diagrams, analysing data from a different perspective, based on digital mapping technology.

As belong to tourism promotion the internet evolution and integration of contemporary digital mapping technology is creating higher possibilities to expose Albanian potentialities.

Actually the tourist communication and information issue has reached at a satisfactory level. Already there are some explanatory and instructing web pages acting as a regulatory pillar toward tourist awareness (figure 1). Most of them offer suitable software's based on digital mapping systems able to give correct and updated directives. The research process, especially based on detached item is mostly covered.

However in Albania there is a noted general lack of tourism databases and inconsistencies in data, which lead to limited applications. Individual entities act as informative institutions based on personal data, creating a sort of confusion and misunderstandings in different population categories. The solutions consist in creating a unique database to be exploited by these organizations unifying their acting policy and directive methods. 
Figure 1

Online Web Mapping Portal, Tirana, Albania

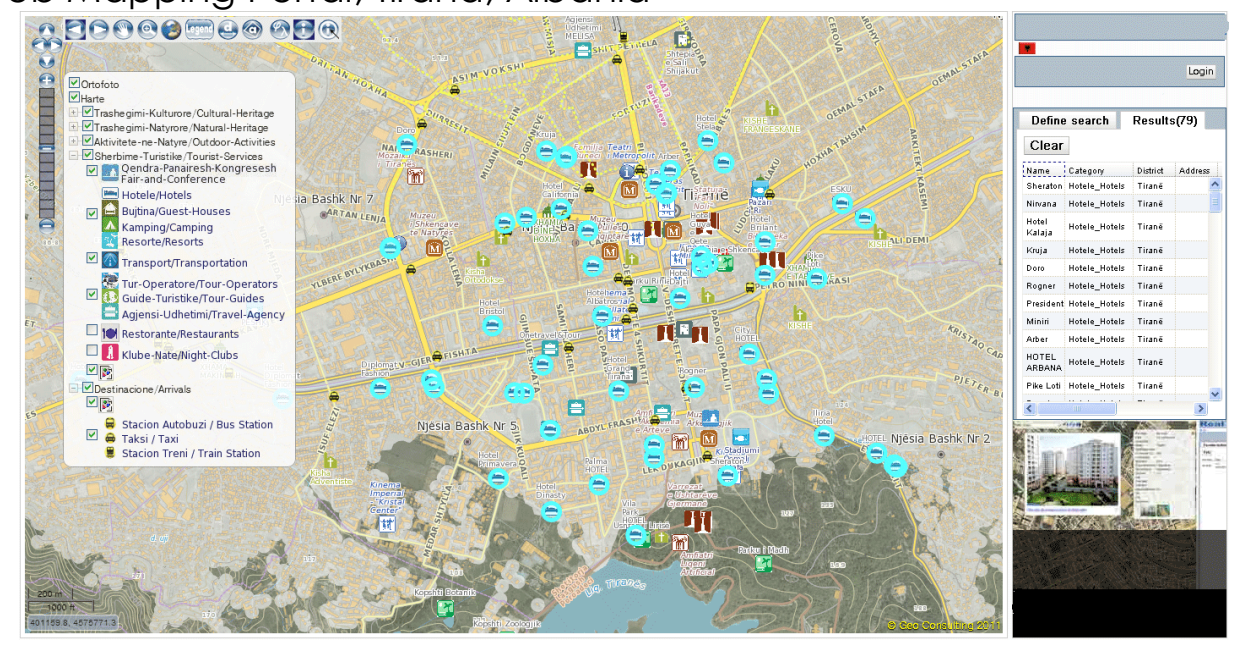

Source: Geo Consulting Albania (GC)

On the other side business information process needs urgent intervention from the responsible institutions in building and supporting a successful tourism sector for a long-term period. The business sector suffers from the same line of problematic related to data inconsistency plus technology integration (figure 2).

Software used during business information requires a higher level of analytical tools than just performing a simple research with the scope of identifying locations. The requirements of a sponsor need to support complex issues affected by a close logical relation. To fulfil the business demands for an extensive data collection it is inevitable to make accumulated data from different sources accessible (Franz et al., 2001).

Figure 2

Communication Technology Platform

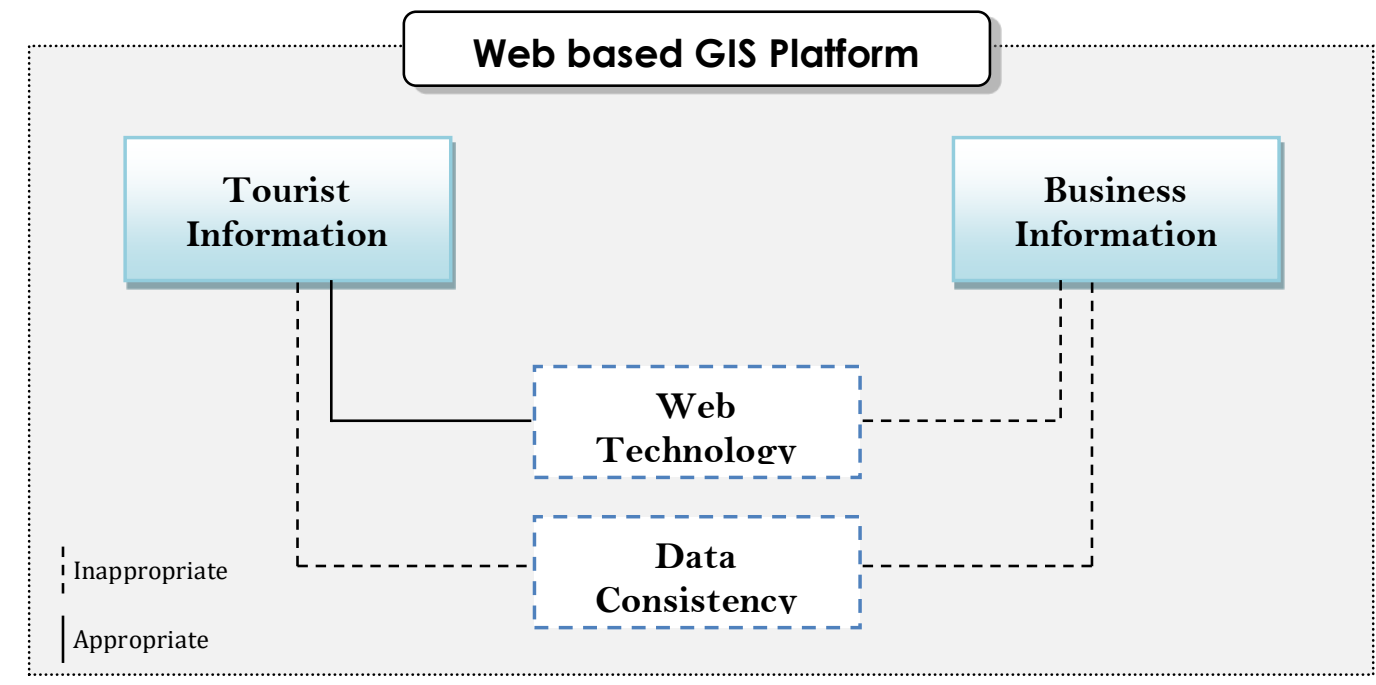

Source: M. Hysenaj, Geographical Information Systems, 2011

GIS technology integrates common database operations such as query and statistical analysis with the uniquevisualisation and geographic analysis benefits 
offered by maps. These abilitiesdistinguish GIS from other information systems and make it valuable to a wide range ofpublic and private enterprises for explaining events (table 1), predicting outcomes, and planningstrategies (ESRI, 2009).

Table 1

Common tourism-related issues and GIS applications

\begin{tabular}{|c|c|}
\hline Problem & GIS Application \\
\hline Benchmark/database & Systematic inventory of tourism resources \\
\hline Environmental management & Facilitating monitoring of specific indicators \\
\hline Conflicts & $\begin{array}{l}\text { Mapping recreational conflicts: recreation wildlife; user } \\
\text { conflict }\end{array}$ \\
\hline Tourism behaviour & Wilderness perceptions \\
\hline Carrying capacity & $\begin{array}{l}\text { Identify suitable locations for tourism/recreation } \\
\text { development }\end{array}$ \\
\hline Prediction & $\begin{array}{l}\text { Simulating and modelling spatial outcomes of } \\
\text { proposed tourism development }\end{array}$ \\
\hline Data Integration & $\begin{array}{l}\text { Integrating socio-economic and environmental } \\
\text { datasets within a given spatial unit }\end{array}$ \\
\hline $\begin{array}{l}\text { Development control } \\
\text { and direction }\end{array}$ & Decision support systems \\
\hline
\end{tabular}

Source: Adapted from Butler 1993, p. 33, cited in Bahaire and Elliott-White (1999), p.162

Natural resource management is another problematic issue. As an example we are introducing (figure 3) an indexed map categorizing the Albanian coastal line according to measured quantities of bacteriological pollution (FC-50). Creating a set of digital maps related to natural resource problematic, local authorities and government institutions will be able to structure an exact plan consisting of detailed intervention points based on well-organized emergency groups.

Figure 3

Touristic coastal line pollution, Developed software Arc Map 10

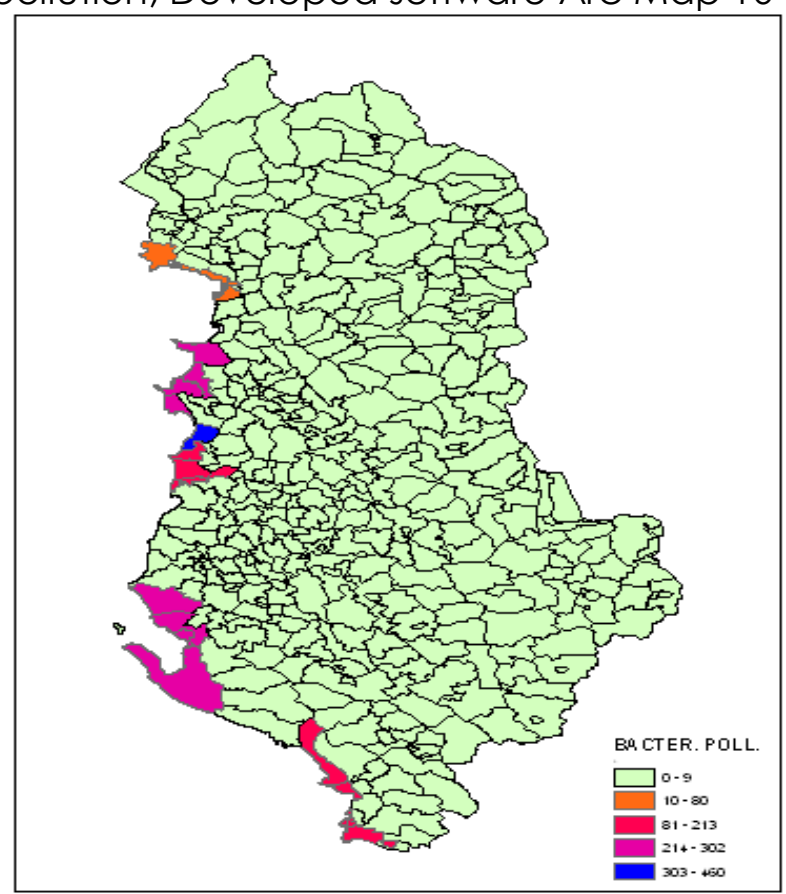

Source: ODA, 2011. 
The insufficient number of accommodation facilities related to the total number of tourists follows the list of concerns for the tourism development. According to statistics (INSTAT, 2010) there are 627 hotels with a capacity of 22743 bed places. During 2010 more than 255 thousand (foreigners \& Albanian citizens) booked in a hotel. Meanwhile "(ODA, 2010)" we face a number of 2.3 million of visitors compared to 1.8 million that was registered only a year ago, reflecting an increment of $29 \%$ within a year. From this amount $63 \%$ belonged to the category of "night-stay" tourists. From a simple calculation we extract an amount of 1 million and 450 thousand tourists that passed at least one night in Albania.

As a conclusion to this set of calculations we derive that approximately only $17.5 \%$ of the total amount of tourists had the opportunity to exploit hotel utilities. This definitely put in evidence the fragile and insufficient infrastructure the Albanian territory represents. In the same time it highlights the importance of future investments and great possibility this sector is offering to the sponsors. With a detailed analysis of the territory (figure 4) followed by an accurate management and operational strategy supported by the right technological tools the hotelier sector can turn into a profitable source of investments.

Figure 4

Hotelier infrastructure distribution, Developed software Arc Map 10

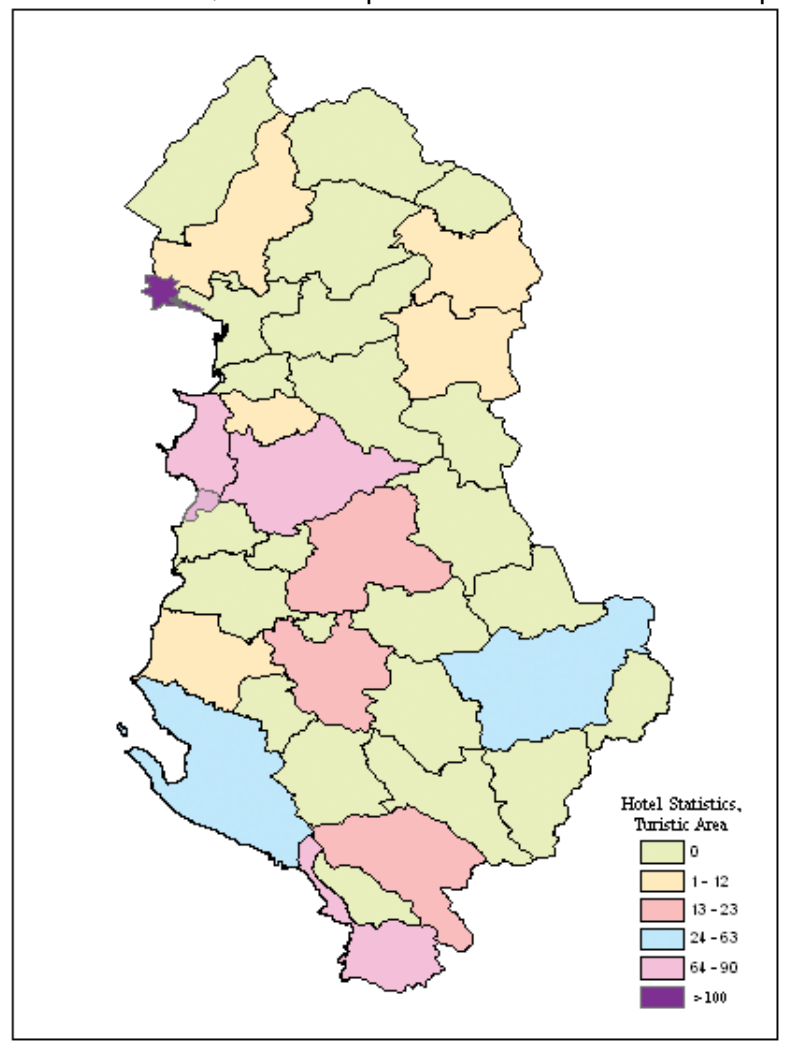

Source: INSTAT, 2011.

\section{Conclusion}

The paper outlines the great potentiality Albanian market can benefit from a well management process of the tourism sector through the integration of contemporary technology. GIS primarily through digital mapping can turn into a potential tool for creating a categorizing structure expressing an indexed list on dynamic maps 
according to the areas and their possible potential of development and investment. The actual Albanian technological infrastructure is continuously improving but still remains much work to do.

According to WEF there is a great handicap between Albanian natural potentialities and responsible institutions policy management. GIS technology offers the right tools for minimizing this handicap through accurate communication and information process including a large category of population. Anyway the greatest efforts must incline basically on business information than tourist information as a more developed field of the informing process. GIS technology integrates common database operations such as query and statistical analysis with the unique visualisation and geographic analysis benefits offered by maps.

In this research GIS application in tourism has been restricted to case illustrations based on a set of digital maps, which have been provided with the scope of creating the first analytical online platform able to act as a management and operational guidance leading to successful decision-making process.

As a continuing study, it would be interesting to evaluate GIS performance in the future relying on more consistent spatial data on tourism locations, behaviours and processes and a larger set of source information's.

\section{References}

1. Ake, D., (2001), "GIS and the tourism industry", SEDA - Council of Governments, Lewisburg.

2. Bahaire, T., Elliott-White, M. (1999), "The application of Geographical Information Systems (GIS) in sustainable tourism planning". International Journal of Sustainable Tourism.

3. ESRI, (2009), "What is GIS ?", available at: http://www.esri.com (15/5/2016)

4. Franz, P., Wolfram, W., (2001), "XML-Based Integration of GIS and Heterogeneous Tourism Information".

5. Hysenaj, M., (2011), "Geographical Information Systems", Shkoder, Albania.

6. Institute of Statistics Albania, (2012), available at: http://www.instat.gov.al/ $(15 / 5 / 2016)$

7. Jovanović, V., Njeguš, A. (2008), "The Application of GIS and its components in Tourism". Volume 18, Issue: 36, page 261-272

8. Kilical, H., Kilical, A., (2003), "Gis as a tool for tourism information management system".

9. Ministry of Tourism, Culture, Youth and Sports (MTKRS), (2011), available at: http://www.mtkrs.gov.al (15/5/2016)

10. Open Data Albania, (2012), available at: http://www.open.data.al (15/5/2016)

11. Sui, D.Z., Goodchild, M.F., (2001), "GIS as media?",int. j. geographical information science, vol. 15, no. 5, 387- 390.

12. Wayne, G., (2003), "GIS applications in Tourism Planning".

\section{About the author}

Medjon Hysenaj works as a lecturer at Shkoder University, since 2006. He received his $\mathrm{PhD}$ degree in 2013. He published the "Geographical Information System" book, 2011 regularly used as didactic material basically for students of Geography science. $\mathrm{He}$ is author of many international articles, as well as many international conferences, mainly covering geospatial topics. The author can be contacted at medjonhysenaj@hotmail.com. 